Terbit online pada laman web jurnal : http://jurnal.iaii.or.id

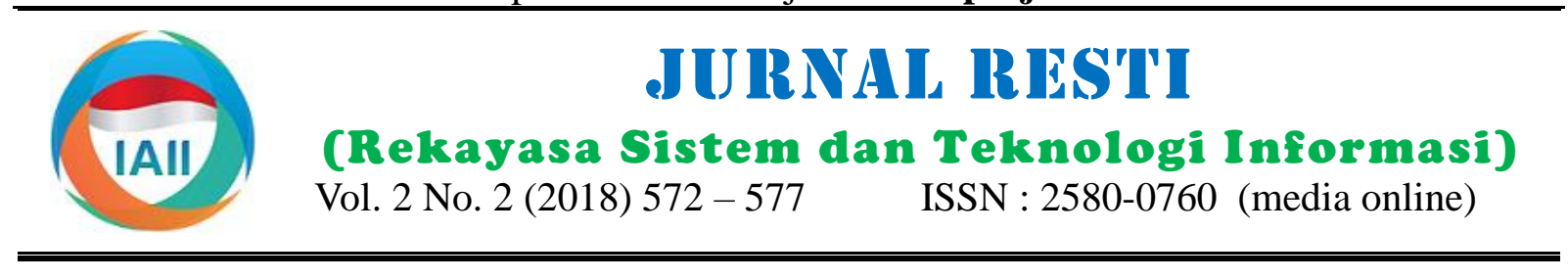

\title{
Pengelompokan Mahasiswa Potensial Drop Out menggunakan Metode Clustering K-Means.
}

\author{
Ieannoal Vhallah $^{\mathrm{a}}$, Sumijan ${ }^{\mathrm{b}}$, Julius Santony ${ }^{\mathrm{c}}$ \\ ${ }^{a}$ Fakultas Ilmu Komputer, Universitas Putra Indoensia YPTK Padang, ieannoal@gmail.com \\ ${ }^{\mathrm{b}}$ Fakultas Ilmu Komputer, Universitas Putra Indonesia YPTK Padang,sumijan@upiyptk.ac.id \\ ${ }^{c}$ Fakultas Ilmu Komputer, Universitas Putra Indonesia YPTK Padang, julius_santony@yahoo.com
}

\begin{abstract}
Clustering K Means is used for grouping. The K-Means method seeks to group the existing data into several unique groups, where data in one group have the same characteristics with each other and have different characteristics than the data exists in the other group. To perform student grouping the potential drop out required attributes. Total Semester Credit System, Comunative Achievement Index, and Total Semester. Clustering process $K$ - Mean is done by determining the nearest initial centroid point in a group of potential drop out students. Clustering results K-Mean by Total Credit System semester, Comulative graduate point, and Total Semester. Results Clustering of potential drop out students for class of 2014 is in cluster 0 are 4 students or $30.77 \%$ of 13 Samples, class of 2015 in cluster 1 are 4 students and cluster 2 are to 2 students or $66.7 \%$ of 9 samples, the force of 2016 is in cluster 0 amounting to 2 students and cluster 1 is 10 students or $50 \%$ from 24 samples, and force of 2017 is in cluster 2 strength 4 student or 22,22\% from 18
\end{abstract}

Keywords:Data Mining, Clustering, K-Means, Potensial Drop Out.

\begin{abstract}
Abstrak
Clustering K Means digunakan untuk melakukan pengelompokan. Metode K-Means berusaha mengelompokkan data yang ada dalam beberapa kelompok yang unik, dimana data dalam satu kelompok memiliki karakteristik yang sama satu sama lainnya dan memiliki karakteristik yang berbeda dengan data di kelompok yang lain. Oleh sebab itu cara ini digunakan untuk melakukan pengelompokan mahasiswa potensi drop out dengan beberapa atribut yaituSistem Kredit Semester Komulatif, Indek Prestasi Kumulatif, dan Semester Kumulatif . Proses Clustering K- Mean dilakukan dengan menentukan titik centroid awal secara acak dalam satu kelompok mahasiswa. Sehingga diperoleh hasil dengan metode K Mean mahasiswa yang potensial drop out, Urntuk angkatan 2014 berada pada cluster 0 berjumlah 4 orang mahasiswa atau 30,77\% dari 13 Sampel, angkatan 2015 berada pada cluster 1 berjumlah 4 mahasiswa dan cluster 2 berjumlah 2 mahasiswa atau 66,7\% dari 9 sampel, angkatan 2016 berada pada cluster 0 berjumlah 2 mahasiswa dan cluster 1 berjumlah 10 mahasiswa atau 50\% dari 24 sampel, dan angkatan 2017 berada pada cluster 2 kekuatan 4 mahasiswa atau 22,22\% dari 18 sampel .
\end{abstract}

Kata Kunci: Data Mining, Klastering, K-Means, Potential Drop Out

(C) 2018 Jurnal RESTI

\section{Pendahuluan}

Pemanfaatan sistem informasi berbasis teknologi komputeryang sudah dimanfaatkan selama bertahun- Data prestasi akademik mahasiswa yang potensial DO tahun menghasilkan jumlah data yang cukup besar. merupakan sebuah data yang sangat penting dalam Data yang dihasilkan tersimpan dalam sistem komputer nenentukan langkah apa yang akan dilakukan sebuah yang dirancang agar cepat dan akurat baik dalam institusi perguruan tinggi. Pola informasi data yang mengoperasikan maupun administrasinya. Kumpulan dihasilkanberfokus pada pengembangan berbagai cara data Prestasi Akademik tersebut memiliki informasi untuk menganalisis jenis data unik di lingkungan untuk pengembangan institusi. Perkembangan pesat pendidikan [2].

Diterima Redaksi : 19-03-2018 | Selesai Revisi : 01-06-2018 | Diterbitkan Online : 02-08-2018 
Data mining adalah langkah analisis dari penemuan Tahap-tahap data mining dapat dijelaskan sebagai pengetahuan dalam databaseatau Knowledge Discovery berikut:

Database (KDD). Untuk menerapkan mengolah data dengan terlebih dahulu harus ditentukan data apa saja yang diperlukan untuk mendapatkan data mahasiswa berpotensi Drop Out (DO).

Teknik data mining denganmetode algoritma clustering $\mathrm{K}$ Means dapat menemukan karakteristik-karakteristik dari nilai prestasi mahasiswa dan menggunakan karakteristik tersebut untuk melakukan pengelompkan (Clustering).

Menggunakan data mining untuk membantu pengembangan kurikulum yang baru dan membantu mahasiswa teknik untuk menseleksi bidang utamanya. [4]. Teknik pemilihan atribut pertambangan adalah pendekatan pilihan atribut berbasis objektif dibandingkan untuk pendekatan seleksi atribut subyektif, yang mengandalkan kajian masa lalu, akal sehat,dan konsultasi berbasis teori, [5].

Perkembangan ilmu pengetahuan dan teknologi yang sangat pesat, akan mendorong sebuah institusi untuk memanfaatkan teknologi tersebut dalam segala bidang, salah satunya system pengolahan data yang sangat cepat dan akurat. Untuk memperoleh data yang akurat tersebut Fakultas Pertanian Universitas Riau memerlukan sebuah sistem pengolahan data mahasiswa yang potensial DO.

\section{Tinjauan Pustaka}

\subsection{Penambangan Data ( Data Mining)}

Data Mining merupakan proses untuk menggali nilai tambah dari sekumpulan data berupa pengetahuan yang selama ini tersembunyi atau tidak diketahui secara manual [3]. Data mining juga dapat digunakan untuk mencari pola- pola data yang dapat dijadikan informasi berharga dengan mengekstrak dan menarik informasi dari basis data yang diperoleh tersebut.

Proses untuk mencari nilai tambah dari sekumpulan data dikenal juga sebagai penemuan pengetahuan dari pangkalan data (Knowledge Discovery in Databases $=$ $K D D)$ yaitu tahap-tahap yang dilakukan dalam menggali pengetahuan dari sekumpulan data. Tahaptahap yang dimaksud terlihat pada Gambar 1 .

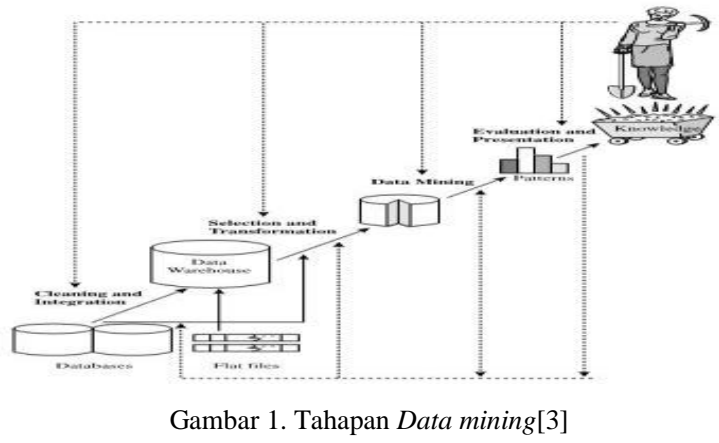

1. Pembersihan data (data cleaning)

2. Integrasi data (data integration )yaitu penggabungan data dari berbagai sumber.

3. Seleksi data (data selection) yaitu memilih data yang sesuai dengan jenis penelitian.

4. Tranformasi data (data transformation)

5. Proses miningEvaluasi pola yang ditemukan (untuk menemukan informasi dan pengetahuan yang menarik).

6. Proses Pola (pattern evaluation).

\subsection{K-Means Clustering}

K-Means Clustering merupakan teknik dalam klaster data yang sangat terkenal karena kecepatannya dalam mengklasterkan data. Akan tetapi K-Means Clustering memiliki kelemahan didalam memproses data yang berdimensi banyak. Khususnya untuk masukan yang bersifat non-linierly separable.

Data akademik mahasiswa bersal dari nilai mahasiswa tiap semester dapat di lakukan clustering dengan etode K-Mean[7]. K-Means clustering juga tidak mampu mengrupkan data yang bertipe kategorikal dan juga data campuran (numeric dan kategorikal) [8].Kenyataan didunia nyata data yang tersedia atau yang diperoleh memiliki dimensi yang banyak dan juga bersifat campuran. Untuk mengatasi permasalahan ini, telah banyak diusulkan oleh parapeneliti metodemetode yang dapat mengatasi kelemahan ini, salah satudi antaranya adalah Kernel K-Means Clustering [6]

Adapun langkah algoritma $K$-means adalah sebagai berikut :

1. Tentukan nilai $k$ sebagai jumlah klaster yang ingin dibentuk.

2. Inisialisasi $k$ sebagai centroid yang dapat dibangkitkan secara random.

$$
\begin{aligned}
& V=\frac{\sum_{i=1}^{n} x i}{n} \ldots \ldots \ldots \ldots \ldots \ldots \ldots \ldots \ldots \ldots \ldots \ldots \ldots \ldots \ldots \ldots \ldots \\
& \text { Dimana } \\
& V=\text { Centroid } \\
& x i=\text { Objek ke i } \\
& n=\text { Banyaknya Objek yang menjadi anggota } \\
& \text { cluster }
\end{aligned}
$$

3. Hitung jarak setiap data ke masing-masing centroid menggunakan persamaan Euclidean Distance yaitu sebagai berikut.

$$
\begin{aligned}
& d\left(X_{j}, C_{J}\right)=\sqrt{\sum_{j=1}^{n}\left(X_{j}, C_{j}\right)^{2}} \ldots \\
& \text { Dimana } \\
& \mathrm{d}=\text { Jarak } \\
& \mathrm{j}=\text { Banyak Data } \\
& \mathrm{c}=\text { Centroid } \\
& \mathrm{x}=\text { Data }
\end{aligned}
$$


4. Kelompokkan setiap data berdasarkan jarak terdekat antara data dengan centroidnya.

5. Tentukan posisi centroid baru $(\mathrm{k})$

Kembali ke langkah 3 jika posisi centroid baru dengan centroid lama tidak sama.

\section{Metodologi Penelitian}

Pada tahap awal penelitian dilakukan dengan cara mengambil data mahasiswa pada Bagian Akademik Fakultas Pertanian Universitas Riau melalui persetujuan Dekan, setelah mengirim surat terlebih dahulu untuk mendapatkan data tersebut, data tersebut akan menjadi subjek penelitian, yaitu berupa Indek Prestasi Kumulatif, SKS Kumulatif dan Tahun Masuk. Kemudian data tersebut di olah dengan menggunakan metode Clustering K Means.

\subsection{Kerangka Kerja Penelitian.}

Untuk memudahkan dalam melakukan penelitianperlu dibuat alur kerangka kerja yang akan dilakukan pada penelitian ini. Alur kerangka kerja penelitian digambarkan dalam diagram aktivitas pada ( Gambar 2) suatu target yang akan dicapai untuk mengatasi masalah-masalah yang ada.

4. Studi literatur

Setelah melakukan identifikasi masalah, kemudian menganalisa data dan menetukan tujuan, langkah selanjutnya adalah mempelajari literatur yang berhubungan dengan judul.Sumber literatur didapatkan dari buku, jurnal, artikel, yang membahas tentang Metode K Mean Clustering,data mining dan bahan bacaan lain yang mendukung penelitian.

5. Pengumpulan data.

Dalam tahap pengumpulan data untuk proses K-Means dilakukan beberapa cara yaitu :

a. Melakukan pengambilan data dari data base Akademik Mahasiswa yang ada di Fakultas Pertanian Unversitas Riau melalui persetujuan Dekan.

b. Melakukan studi pustaka dengan membaca bukubuku dan jurnal ilmiah yang berhubungan dengan permasalahan untuk dapat menganalisis data dan informasi yang dibutuhkan.

\subsection{Analisis Data}

Analisis data diperlukan untuk mendapatkan data yang sesuai dengan kriteria- kriteria untuk pengelompokan mahasiswa yang potensial drop out dengan metode clustering K Means. Data akademik yaitu data nilai yang bersumber dari Hasil studi mahasiswa setiap semester [20]

Untuk dapat melakukan analisis dan penglompokan dari mahasiswa yang berpotensial drop out diperlukan data sampel, dimana data sampel yang akan digunakan dalam penelitian ini diperoleh dari bagian administrasi dan akademik Fakultas Pertanian Universitas Riau.

Metode pengumpulan data yang digunakan yaitu : wawancara, mengambil data akademik Mahasiswa Gambar 2. Kerangka Penelitian.

Berdasarkan kerangka kerja penelitian di atas, maka masing-masing langkahnya dapat diuraikan seperti berikut ini:

1. Identifikasi masalah

Pada tahap inidilakukan proses penentuan masalah dan mendefenisikanbatasan masalah yang akan diteliti, sehiggatujuan penelitian dapat tercapai dengan baik.

2. Menganalisis Masalah pada bagian Administrasi Akademik data berupa Sistem Kredit Semester Total ( SKS Total), Indek Prestasi (IP) dan Semester untuk mahasiswa Angkatan 2014,2015, 2016 dan 2017 periode semester Ganjil 2017/2018 yang memiliki IPK $\leq 2,50$ dari 1696 Mahasiswa Aktif.

Dari seluruh data akademik mahasiswa diambil mahasiswa yang memiliki IPK Kurang dari 2,5 Pada tahap ini dilakukan analisis masalah untuk dapat memahami masalah yang telah ditentukan ruang lingkup atau batasannya. dengan menganalisa masalah yang telah ditentukan tersebut, maka diharapkan masalah dapat dipahami dengan baik.

3. Menentukan tujuan penelitian

Pada tahap ini dikemukakan tujuan yang ingin dicapai melalui proses penelitian. Tujuan penelitian harus jelas dan tegas. Tujuan penelitian adalah
Sehingga didapat data akademik mahasiswa sebanyak 64 mahasiswa yang terdiri dari berbagai program studi Adapun data yang dijadikan objek penelitian ini adalah data Akademik Mahasiswa angkatan 2014, 2015,2016 dan 2017 seperti terlihat pada tabel 1,2,3 dan 4 
Ieannoal Vhallah, Sumijan, Julius Santony

Jurnal RESTI (Rekayasa Sistem dan Teknologi Informasi) Vol.2 No. 2 (2018) 572 - 577

Tabel 1 . Data Akademik Mahasiswa Angkatan 2014.

Tabel4. Data Akademik Mahasiswa Angkatan 2017.

\begin{tabular}{|c|c|c|c|c|c|c|c|c|c|c|c|}
\hline NO & $\begin{array}{l}\text { Kode } \\
\text { Program } \\
\text { Studi } \\
\end{array}$ & NIM & $\begin{array}{l}\text { SKS } \\
\text { Total }\end{array}$ & IPK & Semester & $\mathrm{NO}$ & $\begin{array}{c}\text { Kode } \\
\text { Program } \\
\text { Studi } \\
\end{array}$ & NIM & $\begin{array}{l}\text { SKS } \\
\text { Total }\end{array}$ & IPK & Semester \\
\hline 1 & 54211 & 1406110606 & 132 & 2,5 & 7 & 1 & 54211 & 1706110039 & 23 & 2,15 & 1 \\
\hline 2 & 54211 & 1406111097 & 116 & 2,10 & 7 & 2 & 54211 & 1706110053 & 23 & 2,45 & 1 \\
\hline 3 & 41231 & 1406111311 & 130 & 2,41 & 7 & 3 & 54211 & 1706110199 & 23 & 2,47 & 1 \\
\hline $\begin{array}{l}4 \\
5\end{array}$ & $\begin{array}{l}41231 \\
54211\end{array}$ & $\begin{array}{l}1406112089 \\
1406112491\end{array}$ & $\begin{array}{l}114 \\
125\end{array}$ & $\begin{array}{l}1,89 \\
2,27\end{array}$ & $\begin{array}{l}7 \\
7\end{array}$ & 4 & 54201 & 1706111300 & 23 & 0,52 & 1 \\
\hline 6 & 41231 & 1406113572 & 128 & 2,29 & 7 & 5 & 54211 & 1706111469 & 23 & 2,4 & 1 \\
\hline 7 & 54211 & 1406114014 & 121 & 2,06 & 7 & 6 & 54211 & 1706113534 & 23 & 1,76 & 1 \\
\hline 8 & 41231 & 1406118121 & 108 & 2,05 & 7 & 7 & 54251 & 1706113761 & 23 & 2,5 & 1 \\
\hline $\begin{array}{r}9 \\
10\end{array}$ & 41231 & 1406119543 & 140 & 2,41 & $\begin{array}{l}7 \\
7\end{array}$ & 8 & 54211 & 1706113899 & 23 & 2,32 & 1 \\
\hline $\begin{array}{l}10 \\
11\end{array}$ & 54211 & 1406119994 & 130 & 2,50 & $\begin{array}{l}7 \\
7\end{array}$ & 9 & 54211 & 1706114189 & 23 & 2,5 & 1 \\
\hline 12 & 41231 & 1406120661 & 132 & $\begin{array}{l}2,20 \\
2,37\end{array}$ & 7 & 10 & 41211 & 1706114360 & 23 & 0,78 & 1 \\
\hline 13 & 41231 & 1406122333 & 133 & 2,08 & 7 & 11 & 54211 & 1706121775 & 23 & 2,46 & 1 \\
\hline \multirow{2}{*}{\multicolumn{6}{|c|}{ Tabel2 .Data Akademik Mahasiswa Angkatan 2015.}} & 12 & 54251 & 1706122128 & 23 & 0,85 & 1 \\
\hline & & & & & & 13 & 54201 & 1706122256 & 23 & 2,5 & 1 \\
\hline \multirow[t]{3}{*}{ NO } & Kode & NIM & SKS & IPK & Semester & 14 & 54201 & 1706122514 & 23 & 2,37 & 1 \\
\hline & Program & \multirow{2}{*}{\multicolumn{4}{|c|}{ Total }} & 15 & 41231 & 1706122543 & 23 & 2,28 & 1 \\
\hline & $\begin{array}{c}\text { Studi } \\
41231\end{array}$ & & & & & 16 & 41211 & 1706123003 & 23 & 1,09 & 1 \\
\hline 1 & $\begin{array}{l}41231 \\
54211\end{array}$ & 1506111917 & 90 & $2,4 /$ & $J$ & 17 & 54211 & 1706123213 & 23 & 2,24 & 1 \\
\hline 3 & 54211 & 1506115433 & 96 & 2,28 & 5 & 18 & 54201 & 1706195298 & 24 & 2,4 & 1 \\
\hline
\end{tabular}

$4 \quad 54211 \quad 1506115758 \quad 95 \quad 2,05 \quad 5$

$\begin{array}{llllll}5 & 41231 & 1506115915 & 92 & 2,45 & 5\end{array}$

$\begin{array}{llllll}6 & 54201 & 1506120376 & 94 & 2,50 & 5\end{array}$

$\begin{array}{llllll}7 & 54211 & 1506121197 & 99 & 2,39 & 5\end{array}$

$\begin{array}{llllll}8 & 54211 & 1506121882 & 101 & 2,28 & 5\end{array}$

\begin{tabular}{llllll}
9 & 54211 & 1506122428 & 102 & 2,46 & 5 \\
\hline
\end{tabular}

\begin{tabular}{llllll}
\multicolumn{6}{c}{ Tabel3.Data Akademik Mahasiswa Angkatan 2016.} \\
\hline NO & Kode & NIM & SKS & IPK & Semester \\
& $\begin{array}{l}\text { Program } \\
\text { Studi }\end{array}$ & & Total & & \\
\hline 1 & 54211 & 1606110158 & 61 & 2,46 & 3 \\
2 & 54211 & 1606110854 & 62 & 2,44 & 3 \\
3 & 54201 & 1606111155 & 59 & 1,81 & 3 \\
4 & 54201 & 1606111741 & 55 & 1,52 & 3 \\
5 & 41231 & 1606112063 & 62 & 2,4 & 3 \\
6 & 54201 & 1606112142 & 59 & 2,45 & 3 \\
7 & 54211 & 1606112190 & 62 & 2,27 & 3 \\
8 & 54201 & 1606114469 & 62 & 2,46 & 3 \\
9 & 54251 & 1606116026 & 59 & 2,08 & 3 \\
10 & 54211 & 1606121705 & 62 & 2,36 & 3 \\
11 & 54251 & 1606122632 & 53 & 1,12 & 3 \\
12 & 41231 & 1606123114 & 59 & 1,93 & 3 \\
13 & 54201 & 1606123607 & 56 & 2,2 & 3 \\
14 & 54211 & 1606123807 & 65 & 2,5 & 3 \\
15 & 41211 & 1606136722 & 56 & 2,35 & 3 \\
16 & 41211 & 1606136744 & 50 & 1,7 & 3 \\
17 & 41211 & 1606136940 & 59 & 2,29 & 3 \\
18 & 41211 & 1606136945 & 62 & 2,38 & 3 \\
19 & 41211 & 1606136949 & 62 & 2,35 & 3 \\
20 & 41211 & 1606136952 & 62 & 2,4 & 3 \\
21 & 41211 & 1606136959 & 56 & 2,13 & 3 \\
22 & 41211 & 1606137090 & 65 & 2,19 & 3 \\
23 & 41211 & 1606137278 & 62 & 1,78 & 3 \\
24 & 41231 & 1606197494 & 59 & 2,24 & 3 \\
\hline & & & & &
\end{tabular}

\section{Hasil dan Pembahasan}

Pengujian hasil nilai Clustering $\mathrm{K}$ Means mahasiswa yang Potensial Drop Out dilakukan dengan menggunakan Software.

1. Windows 1064 Byte.

2. Microsoft Office Excel 2016 digunakan sebagai pengolah bahan penelitian

3. Rapid Miner Studio 8.0 merupakan tool untuk pengujian metode Clustering K Means.

Setelah dilakukan perhitungan secara manual dengan metode Clustering $K$ - Means, maka dilakukan pengujian dengan melakukan langkah atau mekanisme pengujian sebagai berikut :

a. Membuat suatu kasus uji yaitu pengumpulan data yang dibutuhkan dalam pengujian dengan perangkat lunak.

b. Menentukan hasil yang diharapkan yaitu hasil klasifikasi dengan melakukan proses perhitungan secara manual.

c. Melakukan evaluasi dilakukan dengan cara membandingkan hasil yang didapatkan pada tahap implementasi sistem dengan hasil yang dibuat secara manual.

\subsection{Hasil Clustering K-Means.}

Hasil dari proses clustering K-Means dengan mengunakan persamaan Euclidean Distancedengan jumlah Cluster 3 danCentroid Awal C0 = ( 114; 1,890; $7), \mathrm{C} 1=(140 ; 2,410 ; 7), \mathrm{C} 3=(129 ; 2,280 ; 7)$ sehingga didapatkan hasil seperti pada Tabel 5 
Ieannoal Vhallah, Sumijan, Julius Santony

Jurnal RESTI (Rekayasa Sistem dan Teknologi Informasi) Vol.2 No. 2 (2018) 572 - 577

\begin{tabular}{ccccc}
\multicolumn{5}{c}{ Tabel 5. Iterasi 2 Angkatan 2014. } \\
\hline NIM & $\begin{array}{c}\text { SKS } \\
\text { Total }\end{array}$ & IPK & Semester & $\begin{array}{c}\text { Jarak } \\
\text { Terdekat }\end{array}$ \\
\hline 1406110606 & 132 & 2,50 & 7 & cluster2 \\
1406111097 & 116 & 2,10 & 7 & cluster 0 \\
1406111311 & 130 & 2,41 & 7 & cluster 2 \\
1406112089 & 114 & 1,89 & 7 & cluster 0 \\
1406112491 & 125 & 2,27 & 7 & cluster 2 \\
1406113572 & 128 & 2,29 & 7 & cluster 2 \\
1406114014 & 121 & 2,06 & 7 & cluster 0 \\
1406118121 & 108 & 2,05 & 7 & cluster 0 \\
1406119543 & 140 & 2,41 & 7 & cluster 1 \\
1406119994 & 130 & 2,50 & 7 & cluster 2 \\
1406120577 & 129 & 2,28 & 7 & cluster 2 \\
1406120661 & 132 & 2,37 & 7 & cluster 2 \\
1406122333 & 133 & 2,08 & 7 & cluster 2 \\
\hline
\end{tabular}

\begin{tabular}{lllll}
\hline NIM & $\begin{array}{l}\text { SKS } \\
\text { Total }\end{array}$ & IPK & Semester & $\begin{array}{l}\text { Jarak } \\
\text { Terdekat }\end{array}$ \\
\hline 1606112063 & 62 & 2,40 & 3 & Cluster 2 \\
1606112142 & 59 & 2,45 & 3 & Cluster 1 \\
1606112190 & 62 & 2,27 & 3 & Cluster 2 \\
1606114469 & 62 & 2,46 & 3 & Cluster 2 \\
1606116026 & 59 & 2,08 & 3 & Cluster 1 \\
1606121705 & 62 & 2,36 & 3 & Cluster 2 \\
1606122632 & 53 & 1,12 & 3 & Cluster 0 \\
1606123114 & 59 & 1,93 & 3 & Cluster 1 \\
1606123607 & 56 & 2,20 & 3 & Cluster 1 \\
1606123807 & 65 & 2,50 & 3 & Cluster 2 \\
1606136722 & 56 & 2,35 & 3 & Cluster 1 \\
1606136744 & 50 & 1,70 & 3 & Cluster 0 \\
1606136940 & 59 & 2,29 & 3 & Cluster 1 \\
1606136945 & 62 & 2,38 & 3 & Cluster 2 \\
1606136949 & 62 & 2,35 & 3 & Cluster 2 \\
1606136952 & 62 & 2,40 & 3 & Cluster 2 \\
1606136959 & 56 & 2,13 & 3 & Cluster 1 \\
1606137090 & 65 & 2,19 & 3 & Cluster 2 \\
1606137278 & 62 & 1,78 & 3 & Cluster 2 \\
1606197494 & 59 & 2,24 & 3 & Cluster 1 \\
\hline
\end{tabular}

Dari tabel 5 dapat disimpulkan bahwa mahasiswa yang memiliki IPK Paling Kecil atau SKS Paling sedikit adalah mahasiswa yang potensial Drop Out, mahasiswa yang potensial drop out berada pada Cluster 0 .

Hasil dari proses clustering K-Means dengan

Mengunakan persamaan Euclidean Distancedengan Dari Tabel 7 dapat disimpulkan bahwa mahasiswa yang jumlah Cluster 3 dan Centroid $\mathrm{AwalC} 0=(101 ; 2,28$; memmiliki IPK paling kecil atau SKS Paling Sedikit $5), \mathrm{C} 1=(96 ; 2,28 ; 5), \mathrm{C} 2=(94 ; 2,45 ; 5)$ sehingga adalah mahasiswa yang potensial Drop Out, Mahasiwa didapatkan hasil seperti pada Tabel 6

Tabel 6. Tabel Iterasi 2 Angkatan 2015.

\begin{tabular}{cllll}
\hline NIM & $\begin{array}{c}\text { SKS } \\
\text { Total }\end{array}$ & IPK & Semester & Jarak Terdekat \\
\hline 1506110776 & 96 & 2,47 & 5 & Cluster 1 \\
1506111917 & 96 & 2,30 & 5 & Cluster 1 \\
1506115433 & 96 & 2,28 & 5 & Cluster 1 \\
1506115758 & 95 & 2,05 & 5 & Cluster 1 \\
1506115915 & 92 & 2,45 & 5 & Cluster 2 \\
1506120376 & 94 & 2,50 & 5 & Cluster 2 \\
1506121197 & 99 & 2,39 & 5 & Cluster 0 \\
1506121882 & 101 & 2,28 & 5 & Cluster 0 \\
1506122428 & 102 & 2,46 & 5 & Cluster 0 \\
\hline
\end{tabular}

yang potensial drop out berada pada Cluster 0 dan Cluster 1.

Hasil dari proses clustering K-Means dengan mengunakan persamaan Euclidean Distancedengan jumlah Cluster 3 dan Centroid Awal C0 $=(24 ; 2,40$; $1), \mathrm{C} 1=(23,00 ; 2,32 ; 1) \cdot \mathrm{C} 2=(23,00 ; 0,85 ; 1$ )sehingga didapatkan hasil seperti pada Tabel 8

Tabel 8. Tabel Iterasi 2 Angkatan 2017.

\begin{tabular}{lllll}
\hline NIM & $\begin{array}{l}\text { SKS } \\
\text { Total }\end{array}$ & IPK & Semester & $\begin{array}{l}\text { Jarak } \\
\text { Terdekat }\end{array}$ \\
\hline 1706110039 & 23 & 2,15 & 1 & Cluster 1 \\
1706110053 & 23 & 2,45 & 1 & Cluster 1 \\
1706110199 & 23 & 2,47 & 1 & Cluster 1 \\
1706111300 & 23 & 0,52 & 1 & Cluster 2 \\
1706111469 & 23 & 2,40 & 1 & Cluster 1 \\
1706113534 & 23 & 1,76 & 1 & Cluster 1 \\
1706113761 & 23 & 2,50 & 1 & Cluster 1 \\
1706113899 & 23 & 2,32 & 1 & Cluster 1 \\
1706114189 & 23 & 2,50 & 1 & Cluster 1 \\
1706114360 & 23 & 0,78 & 1 & Cluster 2 \\
1706121775 & 23 & 2,46 & 1 & Cluster 1 \\
1706122128 & 23 & 0,85 & 1 & Cluster 2 \\
1706122256 & 23 & 2,50 & 1 & Cluster 1 \\
1706122514 & 23 & 2,37 & 1 & Cluster 1 \\
1706122543 & 23 & 2,28 & 1 & Cluster 1 \\
1706123003 & 23 & 1,09 & 1 & Cluster 2 \\
1706123213 & 23 & 2,24 & 1 & Cluster 1 \\
1706195298 & 24 & 2,40 & 1 & Cluster 0 \\
\hline
\end{tabular}

Dari Tabel 8 dapat disimpulkan bahwa mahasiswa yang memmiliki IPK paling kecil atau SKS Paling Sedikit 
adalah mahasiswa yang potensial Drop Out, Mahasiwa prestasi akademik dengan atribut SKS Total, IPK dan yang potensial drop out berada pada Cluster 2 . Semester, dan membandingkan hasil metode ini dengan metode hierarchical clustering, partitional clustering,

\section{Kesimpulan.}

\subsection{Simpulan}

Berdasarkan hasil analisis dan pengujian yang dilakukan terhadap prestasi akademik mahasiswa berupa SKS Total, IPK dan Semester terhadap mahasiswa potensial drop out pada Fakultas Pertanian Unversitas Riau, maka dapat disimpulkan bahwa

1. Dengan Menerapkan Metode Clustering K-Means dapat diketahui mahasiswa potensial drop out lebih dini, sehingga dapat dilakukan pembinaan untuk peningkatan prestasi akademik mahasiswa agar terhindar dari drop out.

2. Dengan mengelompokkan mahasiswa dengan beberapa cluster maka dapat diketahui bahwa hasil clustering angkatan 2014 berada pada cluster 0 berjumlah 4 orang mahasiswa atau 30,77\% dari 13 Sampel, angkatan 2015 berada pada cluster 1 berjumlah 4 mahasiswa dan cluster2 berjumlah 2 mahasiswa atau 66,7\% dari 9 sampel, angkatan 2016 berada pada cluster0 berjumlah 2 mahasiswa dancluster 1 berjumlah 10 mahasiswa atau 50\% dari 24 sampel, dan angkatan 2017 berada pada cluster 2 berjumlah 4 mahasiswa atau 22,22\% dari 18 sampel dan angkatan 2017 terdapat 4 mahasiswa yang potensial drop out.

3. Dengan menggunakan Metode Clustering K- Mean dan software tool dengan menggunakan atribut SKS Total, IPK dan Semester dapat diketahui mahasiswa yang potensial drop out dapat diketahui lebih dini.

\subsection{Saran}

Diarankan agar dilakukan penelitian lebih lanjut terhadap mahasiswa potensial drop out berdasarkan single linkage, complete linkage, average linkage, DBSCAN, Fuzzy C-Means, Self-Organizing Map, KModes dan lain-lain.

\section{Daftar Rujukan}

[1] Xiaowei X., Dewen Z., Wenayo X., Yiyu S., dan Yu H., 2017 "An Efficient Memristor-based Distance Accelerator for Time Series Data Mining on Data Centers.", IEEE Explore No. 17241385.

[2] Rui M., Ding L., Yue L., Lu L., Shujun X., Qian W dan Wenbin F, 2016" Discovery of Acupoints and Combinations for the Moxibustion Treatment of Cervical Radiculopathy: A Data Mining Analysis “, IEEE Explore, N0. 17027672

[3] Han,J. and Kamber,M. "Data mining: Concepts and Techniques", 2nd edition. The Morgan Kaufmann series in Data Management System, Jim Grey, series Editor. 2006.

[4] Sajadin S, Embong. A, Mohammad, M. A, Furqan.M, 2009 " Improving Student Academik Performance Using Data Mining Techniques". Proceeding The 5th IMTGT International Conference on Mathematic, Statistics and Their Application (ICMSA 2009), ISBN 978-602-95343-0-6, Hal 390-394.

[5] Getachew B. D., Tsegaye T., dan Yared B., 2017 "Data Mining Attribute Selection Approach For Drought Modelling: A Case Study For Greater Horn Of Africa”, IJDKP, Volume 7, No 4 Hal 1-15

[6] I.S. Dhillon, Y. Guan, and J. Kogan, 2002. "Iterative clustering of High Dimensional text data augumented by local search. In Proceedings of the 2002 IEEE International Conference on Data Mining Pages, 131-138.

[7] Asroni., dan Ronald A., 2015, "Penerapan Metode K-Means Untuk Clustering Mahasiswa Berdasarkan Nilai Akademik Dengan Weka Interface Studi Kasus Pada Jurusan Teknik Informatika UMM Magelang": Jurnal Ilmiah Semesta Teknika Volume 18 No 1: H 76-82

[8] Govinda R.S, 2015 "Performance Validation of the Modified KMeans Clustering Algorithm Clusters Data “ ,International Journal of Scientific \& Engineering Research Volume 6 Issue 10 Hal 726-730 